\title{
An Early Examination of Access to Select Orphan Drugs Treating Rare Diseases in Health Insurance Exchange Plans
}

\author{
Sandy W. Robinson, MPA; Kelly Brantley, MPH; \\ Christine Liow, MPH; and J. Russell Teagarden, MA, DMH
}

\begin{abstract}
BACKGROUND: Patients with rare diseases often face significant health care access challenges, particularly since the number of available treatment options for rare diseases is limited. The implementation of health insurance exchanges promises improved access to health care. However, when purchasing a plan, patients with rare diseases need to consider multiple factors, such as insurance premium, access to providers, coverage of a specific medication or treatment, tier placement of drug, and out-ofpocket costs.
\end{abstract}

OBJECTIVE: To provide an early snapshot of the exchange plan landscape from the perspective of patients with select rare diseases by evaluating the degree of access to medications in a subset of exchange plans based on coverage, tier placement, associated cost sharing, and utilization management (UM) applied.

METHODS: The selection of drugs for this analysis began by identifying rare diseases with FDA-approved treatment options using the National Institutes of Health Office of Rare Diseases' webpage and further identification of a subset of drugs based on select criteria to ensure a varied sample, including the characteristics and prevalence of the condition. The medications were categorized based on whether alternative therapies have FDA approval for the same indication and whether there are comparators based on class or therapeutic area. The list was narrowed to 11 medications across 7 diseases, and the analysis was based on how these drugs are listed in exchange plan outpatient pharmacy benefit formularies. This analysis focused on 84 plans in 15 states with the highest expected exchange enrollment and included a variety of plan types to ensure that variability in the marketplace was represented. To best approximate plans that will have the greatest enrollment, the analysis focused on silver and bronze plan formularies because consumers in this market are expected to be sensitive to premiums. Data on drug coverage, tier placement, cost, and UM were collected from these plans beginning 0ctober 1, 2013, with the launch of the open enrollment period.

RESULTS: Coverage and use of UM for selected medications vary within and across states. This study found that bronze plans were far less likely than silver plans to cover the 11 products included in this analysis. Results also showed that select drugs identified as the only FDA-approved product indicated for a certain rare disease experienced relatively robust coverage (at least $65 \%$ of plans) but often included some form of UM. However, coverage of selected rare disease therapies also is complicated by the fact that plans cover certain products under the medical benefit versus the pharmacy benefit. At the time of this analysis, transparency of medical benefit coverage for these products in exchange plans was limited. Selected medications are most likely to appear on the highest tiers of 4-tier formularies or are not covered at all. Although there are no requirements to designate certain tiers as "specialty tiers," more than $70 \%$ of plans in this study use coinsurance for the highest tiers of their formularies. Rates of coinsurance for medications on highest tiers range from $10 \%$ to $50 \%$ in silver plans and $15 \%$ to $50 \%$ in bronze plans. Among those plans utilizing copayments rather than coinsurance, ranges of copayments for these select products vary between $\$ 20$ and $\$ 250$ per prescription across both silver plans and bronze plans.
CONCLUSIONS: This preliminary analysis of access to treatments for patients with select rare diseases revealed the complexities involved for patients with specific needs when selecting a plan with appropriate coverage. For patients with rare diseases, the process of identifying and selecting a plan centers on understanding if and how the plan covers a specific treatment or set of treatments. Access factors will likely vary substantially across plans, as demonstrated by the findings from this analysis. With limited treatment options and the potential for cost sharing and UM barriers, increased data transparency to assist patients in navigating formularies will be a critical step for patients to fully understand their access to needed therapies in each plan.

J Manag Care Pharm. 2014;20(10):997-1004

Copyright $\odot 2014$, Academy of Managed Care Pharmacy. All rights reserved.

\section{What is already known about this subject}

The Affordable Care Act mandates the implementation of health insurance exchanges, which promise improved access to health care for those who have not had access to insurance coverage through existing public and private sources.

Drug coverage requirements for exchange plans vary from state to state, and plans have flexibility to control access to covered drugs through tier placement, cost sharing, and utilization management.

\section{What this study adds}

This study provides a preliminary examination of the degree of access to medications that patients with select rare diseases may experience in the inaugural year of the health insurance exchange market.

Coverage, tier placement, associated cost sharing, and utilization management applied for the selected medications in this study.

Tr n $\mathrm{n}$ the United States, a rare disease is defined as one affecting fewer than 200,000 people. ${ }^{1}$ There are more than 6,800 rare - diseases affecting an estimated 25 to 30 million Americans. ${ }^{2}$ Because of the low prevalence of these diseases, investments in new treatment options by researchers and industry face scientific and commercial challenges. This has resulted in patients with rare diseases having a narrow range of treatment choices for their conditions. ${ }^{3}$ While the federal government has put in place incentives to encourage the development of treatments for rare diseases, such as orphan drug designation and humanitarian device exemption policies, coverage for these products 
under insurance plans has been highly variable. ${ }^{4-6}$ In addition, orphan drugs are among the most expensive drugs in the world. ${ }^{7}$ Even when drugs are available, patients with rare diseases may be unable to access these treatments because of high out-of-pocket costs, particularly if they are not already covered under a health insurance plan. These types of access issues are not uncommon for patients with rare diseases. ${ }^{\top}$

The Affordable Care Act (ACA) mandates the implementation of health insurance exchanges, which promises improved access to health care for those who have not had access to insurance coverage through existing public and private sources. Health insurance coverage is a core component of access to appropriate care. However, even with insurance coverage, understanding a patient's access to care is multidimensional and includes examining factors such as plan premiums, availability of specific health care providers, coverage of a specific medication or therapy, utilization management (UM; e.g., prior authorization, step therapy, and quantity limits), patient cost sharing, and the exceptions and appeals processes. The ACA leaves many implementation details at the discretion of participating health plans, and as a result, there is expected to be considerable variation in the medications covered by individual plans. The objective of this study was to provide a preliminary examination of the degree of access to medications that patients with rare diseases may experience in year 1 of the health exchange market.

\section{Essential Health Benefits and Drug Coverage}

A goal of the ACA was to create a market in which choices in insurance products offered could be easily understood and compared by individuals. To that end, the law requires plans participating in the exchanges to fit into 1 of 4 "metal levels" (bronze, silver, gold, and platinum), defined based on the portion of average enrollee spending that is covered by the plan-a concept known as actuarial value (Table 1 ). ${ }^{8}$ These metal levels provided the basis for how plans designed their insurance products, including their drug benefits. They also offer consumers a method for comparing plans that are designed to be actuarially equivalent to one another, using the metal-level marker as an indication of comparability.

In addition, the ACA set minimum standards, called "essential health benefits" (EHBs), to ensure that qualified health plans (QHPs) in the exchanges offer a generally consistent and comprehensive package of items and services. ${ }^{9,10}$ Each state defined EHBs for applicable plans by selecting a "benchmark" plan. States had the discretion to choose from among a set of 10 health insurance plans already existing in the state's current market in 4 federally determined categories of coverage-for example, a state might select 1 of the 3 largest small-group plans in a state's market.

Specific to drug coverage, health plan formularies are required to cover at least the same number of drugs in each United States Pharmacopeia (USP) Model Guideline (Version 5) category and class as found in the state-defined benchmark plan. ${ }^{11,12}$ Every
3 years, USP releases revised Model Guidelines that offer a template for Medicare Part D plans to use to structure their formularies, organizing Part D-covered drugs into an organizational system. USP groups all Part D drugs into 50 therapeutic categories, groupings typically based on the diseases or symptoms treated by these drugs. Then USP further classifies most categories into distinct pharmacologic classes, which are based largely on their mechanisms of action.

The federal government, in announcing the state benchmark plans, released the number of drugs in each category and class covered by each state's benchmark, although the particular drugs covered were not disclosed. This methodology was intended to ensure that health plans meet a minimum standard for outpatient drug coverage. ${ }^{11}$ Meeting the standards established through this counting methodology constitutes fulfillment of federal requirements. ${ }^{13}$ At the same time, this approach creates challenges for plans to ensure that appropriate treatment options are available for all diseases, particularly rare diseases. Additionally, the breadth of state-selected benchmark plan formularies also varies across states, resulting in substantially different coverage requirements from state to state. ${ }^{14}$

\section{Impact on Patients with Rare Diseases}

QHPs are based on commercial coverage for small employers (i.e., the state benchmark plan), which are not typically designed with patients with rare diseases in mind. The ACA established pre-existing condition insurance plans (PCIPs) to help bridge the gap between when the law was passed and when exchanges would be operational. As patients transition from PCIPs to this new marketplace, QHPs will be expected to meet the needs of all enrollees, regardless of health status. Plans must design benefits packages that are both comprehensive and affordable. Treatments for rare diseases pose a challenge to plans as they balance their structure to meet the diverse needs of marketplace enrollees, while also complying with nondiscrimination requirements. To help QHPs accomplish these varied interests, federal regulations afforded plans substantial flexibility to accomplish these many goals.

Given the limited treatment options for patients with rare diseases, these patients will want to ensure access to their needed therapies prior to enrolling in any marketplace plan. When they are covered, higher cost medications, such as those for rare disease therapies, may be placed on a plan's higher formulary tiers. Tier placement and cost sharing may challenge patient access to these medications. In addition to coverage and cost, patients with rare diseases must understand UM techniques, such as prior authorization, step therapy, and quantity limits, which may be applied to their therapies. With rising health care costs, plans are continually balancing medical appropriateness and patient access. Plans use UM to ensure that the most appropriate drug is being utilized.

This study aimed to analyze the variation in exchange plan coverage for 7 rare diseases and the drugs with approved indications for treating those diseases. It was expected that there 


\begin{tabular}{l|l}
\hline \multicolumn{1}{c|}{ TABLE 1 } & Actuarial Value Requirements \\
\hline Bronze & Covers $60 \%$ of health care costs \\
\hline Silver & Covers $70 \%$ of health care costs \\
\hline Gold & Covers $80 \%$ of health care costs \\
\hline Platinum & Covers $90 \%$ of health care costs \\
\hline Note: The actuarial value requirements are based on a typical patient population. \\
\hline
\end{tabular}

would be considerable variation in drug coverage because this is the inaugural year of the exchanges. If commercial insurance coverage of drugs used to treat rare diseases is utilized as a proxy, in general, it was expected that these drugs would be placed on higher formulary tiers, due to their cost. It was also expected that these drugs would be subject to UM that would allow plans to ensure the most appropriate use. Finally, it was uncertain how coverage for physician-administered drugsmost often covered under a commercial insurer's medical benefit—would be listed on exchange websites. For this reason, our analysis focused on pharmacy-benefit coverage only. Findings from this analysis provide a preliminary understanding of variations in drug coverage and UM requirements that patients seeking orphan drugs can expect in the exchange marketplace.

\section{Methods}

This analysis proposed to evaluate coverage and access in a sample of exchange plans for medications used by patients with select rare diseases and to provide an early snapshot of challenges that this subset of the exchange population may face in exchange plans.

To ensure a varied sample of rare diseases and rare disease drugs, we utilized a 2-pronged approach when selecting the diseases and treatments for our analysis. This approach entailed (1) identifying rare diseases that varied in terms of disease states, characteristics, and prevalence under 200,000 cases and (2) identifying available U.S. Food and Drug Administration (FDA)-approved treatment options for a disease that meet 1 of the following groupings:

I. Drugs with orphan drug designations, which are the only drug the FDA approved to treat a particular rare disease.

II. Drugs with orphan drug designations that have an FDAapproved indication for a particular rare disease and FDA approval for at least 1 nonorphan indication.

III. Drugs that share orphan drug designations and FDAapproved indications for the same rare disease.

We used the National Institutes of Health (NIH) Office of Rare Diseases' "Rare Diseases with FDA-Approved Medical Products" webpage as the initial source for selecting rare diseases and medications. ${ }^{15}$ This webpage contains an indexed list of rare diseases and a corresponding list of FDA-approved drugs indicated for each specified rare disease. From the hundreds of rare diseases included on the NIH website, we selected an initial subset of 15 diseases based on the preliminary disease-specific criteria. Within this list, we identified 23 FDA-

\begin{tabular}{|c|c|c|c|}
\hline & Generic Name & Trade Name & $\begin{array}{c}\text { Rare Disease } \\
\text { Approved Indications }\end{array}$ \\
\hline \multirow{5}{*}{ I } & Tetrabenazine & Xenazine & Huntington disease \\
\hline & Albendazole & Albenza & $\begin{array}{l}\text { Hydatid disease and } \\
\text { neurocysticercosis }\end{array}$ \\
\hline & Cinacalcet & Sensipar & $\begin{array}{l}\text { Hypercalcemia secondary to } \\
\text { parathyroid carcinoma and } \\
\text { severe primary hypercalcemia, } \\
\text { when parathyroidectomy not } \\
\text { possible }\end{array}$ \\
\hline & Eculizumab & Soliris & $\begin{array}{l}\text { Atypical hemolytic uremic } \\
\text { syndrome and paroxysmal } \\
\text { nocturnal hemoglobinuria }\end{array}$ \\
\hline & Hydroxyurea & Droxia & Sickle cell anemia \\
\hline II & Pazopanib & Votrient & $\begin{array}{l}\text { Advanced soft tissue sarcoma } \\
\text { in patients who had received } \\
\text { chemotherapy }\end{array}$ \\
\hline \multirow{5}{*}{ III } & Alglucerase & Ceredase & \multirow{5}{*}{ Gaucher disease, type 1} \\
\hline & Imiglucerase & Cerezyme & \\
\hline & Taliglucerase alfa & Elelyso & \\
\hline & Velaglucerase alfa & Vpriv & \\
\hline & Miglustat & Zavesca & \\
\hline
\end{tabular}

approved treatment options across the diseases. Because the webpage notes that drug lists may not be exhaustive, we crossreferenced the drug list from the NIH webpage with the FDA's orphan drug database to ensure that we captured all current FDA-approved medications indicated for a specific disease. ${ }^{16}$

From this initial subset, we further narrowed the list to 11 medications across 10 diseases that could be categorized according to the grouping structure previously described. Key factors for this classification included the drug's FDA approval for a particular condition, whether other medications have FDA approval for the same indication, and if the drug has comparators based on class or therapeutic area. The rare diseases included in this study are Huntington disease, hydatidosis, parathyroid carcinoma, atypical hemolytic uremic syndrome, sickle cell anemia, advanced soft tissue sarcoma, and Gaucher disease type 1. Table 2 presents the results of the drug selection as well as the classification of each into groupings.

As noted earlier, health plans may cover medications under their medical benefit rather than pharmacy benefit, and this distinction may not be detailed on the plan's summary of benefits materials describing drug coverage. Of the products included in our analysis, Soliris, Ceredase, Cerezyme, Elelyso, and Vpriv could potentially be covered under an exchange plan's medical benefit, rather than the pharmacy benefit due to their formulation and labeling for health care professional administration. ${ }^{17-21}$ At the time of analysis, medical coverage policies for new exchange plans were generally not widely available, so this analysis does not include medical coverage of these medications. This analysis focused solely on coverage of select rare disease therapies as listed in exchange plan outpatient pharmacy benefit formularies. 


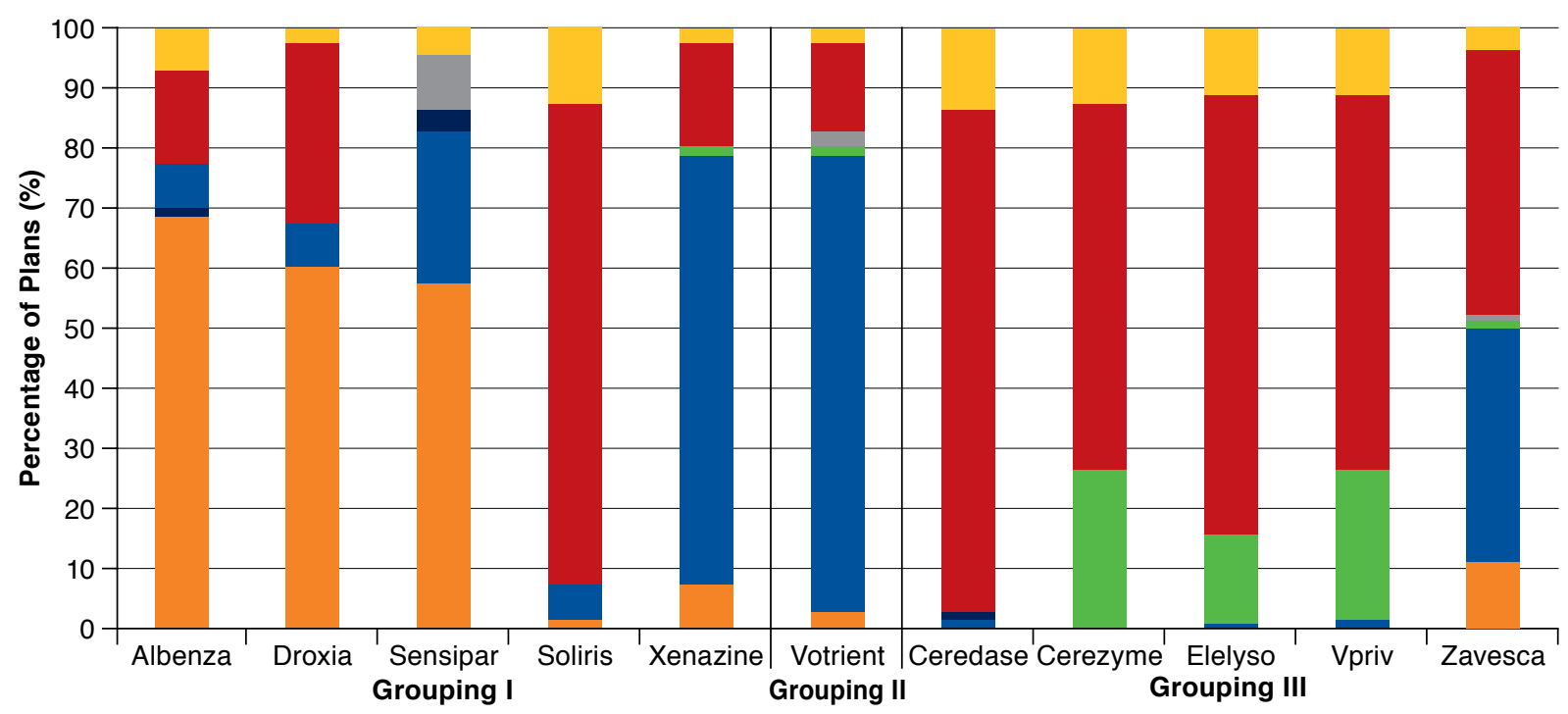

\begin{tabular}{|llll|}
\hline Covered-No UM & Covered-PA & Covered-PA/ST & Not Listed \\
& Covered-ST & Covered-Other UM & No Data \\
\hline
\end{tabular}

Source: Avalere Health PlanScape, a proprietary analysis of exchange plan features. Data as of October 31, 2013.

Note: Soliris, Ceredase, Cerezyme, Elelyso, and Vpriv may be covered under the medical benefit; data presented includes pharmacy benefit coverage only. $P A=$ prior authorization; Other UM=any other UM, such as quantity limits or age/gender limits; ST=step therapy; UM=utilization management.

To select a subset of plans for this analysis, we focused on 15 states with the highest expected exchange enrollment: California, Texas, Florida, New York, New Jersey, Wisconsin, Pennsylvania, Ohio, North Carolina, Illinois, Georgia, Michigan, Virginia, Arkansas, and Indiana. These states are expected to account for more than $60 \%$ of total exchange enrollment. ${ }^{22}$ The analysis included 84 plans from a randomly selected ZIP code in the largest city in each of these states. For select states in the analysis (Florida, Ohio, Pennsylvania, and Virginia), we included a ZIP code in each of the 2 largest cities in the state. We included a variety of plan types in the analysis, including national, regional, and local plans; Medicaid managed care organizations (MCOs); provider-sponsored plans; and Consumer Operated and Oriented Plans (CO-OPs) to ensure variability in the approaches to benefit designs represented. Our plan selections captured more than $90 \%$ of issuers in the selected ZIP codes for each of the states selected.

To best approximate plans that will have the greatest enrollment, we focused on those with premiums near or below the second-lowest cost silver plan in each state. We expected consumers in the market for exchange plans to be sensitive to premium costs and to enroll disproportionately in plans with the lowest premiums. Additionally, many consumers who are expected to enroll in exchanges will qualify for subsidies that will substantially reduce the cost of silver and bronze plans.
More enrollees are expected to join silver plans because the ACA's tax credits are based on silver plan premiums, and costsharing assistance is tied to these plans. ${ }^{23}$ Consumers eligible for tax credits could apply those credits to bronze plans for even lower monthly premium charges. For these reasons, we focused our analysis on silver and bronze plans and reviewed between 3 and 9 plan formularies in each state.

Exchange plan formulary designs for the 84 selected QHPs were collected beginning October 1, 2013, with the launch of the open enrollment period for exchanges. Given problems with HealthCare.gov and many state exchange websites, formularies used in this analysis were those published on the issuer's website for the 2014 plan year. From these documents, we collected data on drug coverage, tier placement, and UM. This analysis also included cost-sharing requirements, after any plan deductible is met, for a 30-day supply of a medication purchased at a network pharmacy. We considered plans that require coinsurance up to a fixed dollar cap to be requiring coinsurance for that particular formulary tier.

\section{Results}

\section{Drug Coverage and Utilization Management}

Our analysis showed that coverage and rates of UM of select orphan drugs varies considerably. Bronze plans were far less likely than silver plans to cover the selected products in this 
analysis. In fact, only 40\% (6 of 15) of bronze plans covered Votrient- the medication in this analysis with the highest level of coverage among bronze plans-compared with nearly $77 \%$ (53 of 69) of silver plans.

Select drugs identified as being the only FDA-approved product indicated for a certain rare disease (Grouping I) experienced relatively robust coverage (see Figure 1). As expected, access often included some form of UM. Albenza, Droxia, Sensipar, and Xenazine were covered by more than $65 \%$ of plans, with Sensipar, at the highest, being covered by $95 \%$ of plans. Use of UM among these medications ranged widely from $6 \%$ of plans for Albenza to nearly $75 \%$ of plans for Xenazine. Soliris is covered by $8 \%$ of plans, and only $1 \%$ of those plans allow access to the product without prior authorization; however, it is important to note that since Soliris is administered intravenously, QHPs may cover Soliris under the medical benefit, which was not reviewed for this analysis.

Votrient, as a medication indicated for a rare disease and another nonorphan condition (Grouping II), was covered by $82 \%$ of plans; however, only $4 \%$ of the plans allow access to Votrient without UM.

For a scenario where there were several orphan drugs with FDA-approved indications to treat the same rare disease (Grouping III), coverage was generally low and potentially more complex. Ceredase, Cerezyme, Elelyso, Vpriv, and Zavesca are 5 drugs that are approved and indicated for treatment of Gaucher disease, type 1. Zavesca, the only oral medication in this grouping with a mechanism of action to reduce substrate production, is covered by $52 \%$ of plans and has access without UM in $12 \%$ of plans analyzed. Ceredase, Cerezyme, Vpriv, and Elelyso-intravenous medications with mechanisms of action that replace enzymes to clear substrate-experience between $2 \%$ and $26 \%$ of coverage by plans under the pharmacy benefit. Again, these low coverage statistics may not represent a complete picture of the coverage profile of these particular drugs; as injectables, these products are likely to be covered separately under a QHP's medical benefit.

\section{Plan Tier Structure and Cost Sharing}

In general, the majority (62\%) of formularies reviewed have a 4-tier structure, while 19\% of formularies have 5 tiers. Although coverage does vary across the medications in this analysis, exchange plans typically place the products analyzed at tier 3 or above for both 4- and 5-tier formularies. Also, the vast majority (more than 70\%) of selected QHPs use coinsurance (a percentage of health service charges that the patient must pay) for the highest tiers of their formularies. The coinsurance rates in these plans range from $10 \%$ to $50 \%$ in silver plans and $15 \%$ to $50 \%$ in bronze plans. Among those plans utilizing copayments (a flat fee for a prescription or health service) rather than coinsurance, ranges of copayments for all products included in this analysis vary between $\$ 20$ and $\$ 250$ per prescription across both silver and bronze plans.

\section{TABLE 3 Most Common Tier Placement}

\begin{tabular}{l|l|l}
\hline \multirow{4}{*}{ Grouping I } & \multicolumn{1}{|c|}{ Drug Name } & \multicolumn{1}{c}{$\begin{array}{c}\text { Most Common Tier Placement } \\
\text { (4-Tier Formulariesa) }\end{array}$} \\
\hline & Albenza & Tier 3 (57\%) \\
\cline { 2 - 3 } & Droxia & Tier 4 (31\%) \\
\cline { 2 - 3 } & Sensipar & Tier 4 (66\%) \\
\cline { 2 - 3 } & Xenaxine & Tier 4 (64\%) \\
\cline { 2 - 3 } & Soliris & Not listed (79\%) \\
\hline Grouping II & Votrient & Tier 4 (87\%) \\
\hline \multirow{4}{*}{ Grouping III } & Zavesca & Not listed (47\%) \\
\cline { 2 - 3 } & Ceredase & Not listed (87\%) \\
\cline { 2 - 3 } & Cerezyme & Not listed (62\%) \\
\cline { 2 - 3 } & Elelyso & Not listed (77\%) \\
\cline { 2 - 3 } & Vpriv & Not listed (57\%) \\
\hline \multirow{2}{*}{ a67\% of the exchange plans in our sample structured formularies into 4 tiers }
\end{tabular}

Tiering findings for all 11 selected products are detailed in the following section. An overview of product tier placement on 4-tier formularies, the most common formulary structure in exchange plans, is provided in Table 3. Cost-sharing details for the 6 selected products covered mainly under the pharmacy benefit are depicted in Figure 2.

Across the 11 medications, all are most likely to either be placed on the highest tiers of 4-tier formularies (Tier 3 or Tier 4) or not covered altogether. The high tier placement is reflected in Grouping I and II with the exception of Soliris. Zavesca was not covered by nearly half of plans. Due to their formulation, Soliris, Ceredase, Cerezyme, Elelyso, and Vpriv are most commonly not covered under the pharmacy benefit and may be covered under the medical benefit instead, which is consistent with the findings.

For the 6 drugs that are expected to be covered under the pharmacy benefit, coinsurance and copayment rates under silver plans ranged widely. Coinsurance across all 6 drugs ranged from $10 \%$ to $50 \%$, while average coinsurance rates ranged from 27\% (Droxia) to 38\% (Zavesca). Copayment rates across the products ranged from as low as $\$ 20$ to as high as $\$ 250$. Average copayments fell within the range of $\$ 61$ (Albenza) to \$144 (Xenazine).

Finally, the results also showed substantial state-by-state variation in drug coverage for selected medications likely to be covered under the pharmacy benefit (see Table 4).

\section{Discussion}

Across the QHPs examined, measures of access vary from coverage to cost sharing. It is important for patients with rare diseases seeking coverage in the exchanges to, at minimum, examine plan formularies prior to enrolling in an exchange plan. They should also look closely at the tier placement and associated cost sharing, as well as UM policies to ensure that they can access needed medications. Further, the USP-based counting methodology assessing formulary adequacy may create artificial boundaries on drug coverage and, as a result, limit 

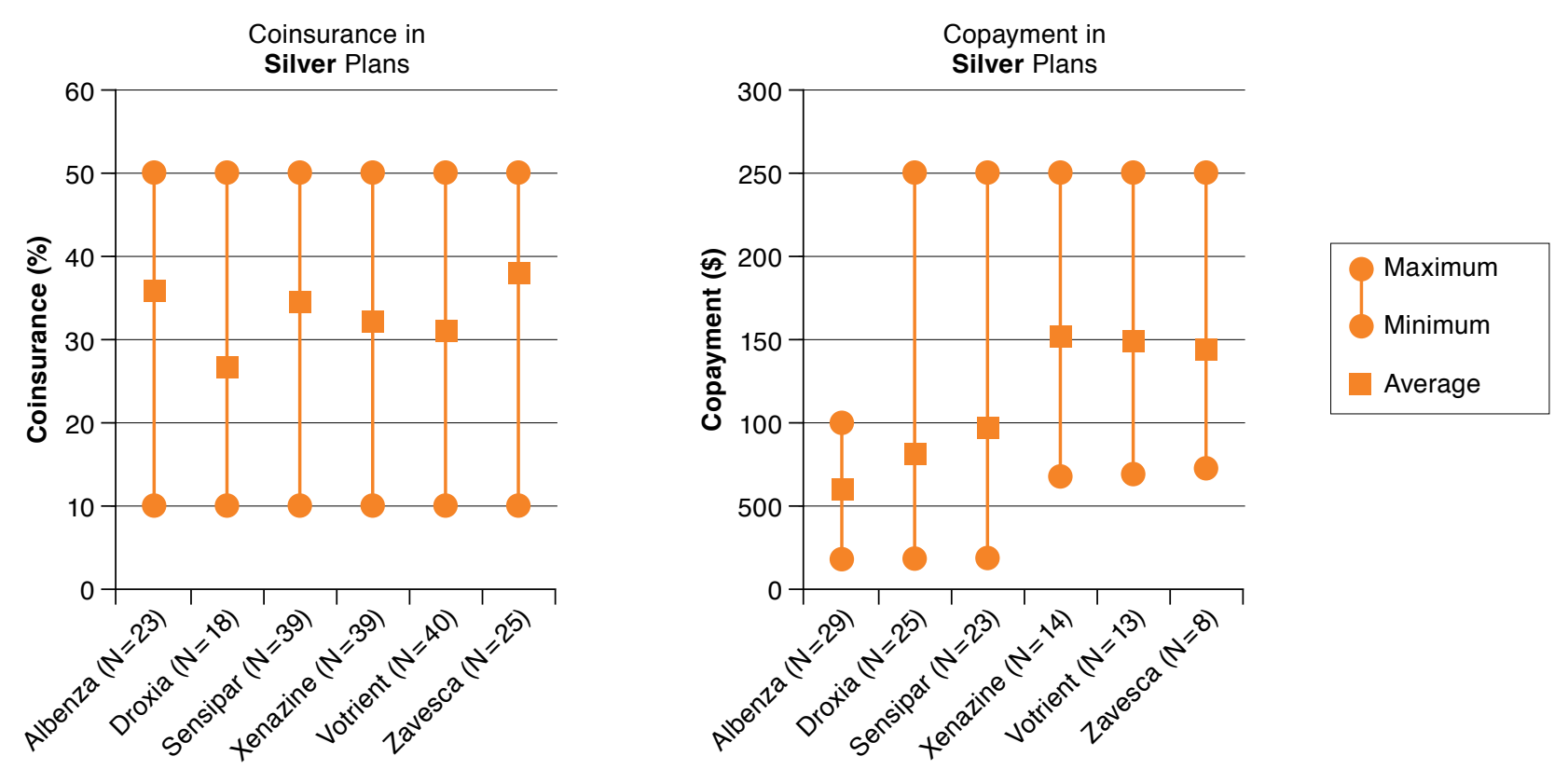

Source: Avalere Health PlanScape, a proprietary analysis of exchange plan features. Data as of October 31, 2013.

Note: $N=$ numbers of plans that use coinsurance or copayment for that product. Plans that require coinsurance with a copayment cap (i.e., $25 \%$ coinsurance up to $\$ 300$ ) are treated as requiring coinsurance for this analysis.

medication access for rare conditions. In addition, patients with rare conditions will also need to consider coverage of treatments under the medical benefit policies of the QHPs.

Due to federal standards for benefit design in the metal plan levels given the actuarial value requirements, QHPs must balance the cost of and access to certain medications while maintaining the set actuarial value levels (Table 1). Due to their higher cost, it is not surprising that the orphan drugs in this analysis are often placed on the higher tiers of QHP formularies. Because higher tier placement is coupled with higher cost sharing, patients may face substantial out-of-pocket expenses. Depending on the plan, patients may experience cost sharing of up to $50 \%$ coinsurance until they meet the out-of-pocket maximum.

Notably, bronze plans in this analysis are less likely to place select orphan drugs on their formularies than silver plans. Given concerns of adverse selection for lower-priced plans, patients with rare diseases who select bronze plans for lower premiums may find limited coverage options for their needed medications. The cost savings from lower premiums may quickly be outweighed by out-of-pocket expenses from higher cost sharing or noncoverage of a therapy. Patients with greater health needs may find more favorable coverage and costs for their needed medicines in higher premium gold and platinum plans than in lower premium plans. A gold or platinum plan may prove to be more cost-effective in the long term for patients than a bronze plan, with higher premiums potentially being offset by reduced out-of-pocket maximums and better coverage.
Actual enrollment data released by the federal government have confirmed the methodological soundness of plan selection for this analysis. The methodology anticipated that most people would enroll in low-cost silver and bronze plans and, thus, focused on these plans. The federal enrollment report on all enrollments during the inaugural open enrollment period validated this hypothesis-in fact, $85 \%$ of enrollees nationwide selected a plan in 1 of these 2 metal levels. ${ }^{24}$ The confirmation of the hypotheses used to develop the methodology indicates the results of this analysis may be more broadly applicable across exchange plans than anticipated. Furthermore, the silver and bronze plans included in this analysis are from the top 15 states by expected exchange enrollment, predicted to represent about $60 \%$ of national enrollment. In fact, actual enrollment data confirmed that exchange enrollment in these states accounted for more than $73 \%$ of total enrollment nationwide.

The out-of-pocket maximum of $\$ 6,350$ for an individual does offer patients with high health expenses substantial financial protection across all metal levels. ${ }^{25}$ At the same time, patients with high health costs could meet the maximum outof-pocket early in a plan year, a substantial sum in a short amount of time. For example, patients in Connecticut who purchase a standard silver plan and take a rare disease therapy costing $\$ 15,000$ per month will reach their out-of-pocket maximum by the second month of enrollment. In the first month, the patient will pay the full cost of the plan's drug deductible 


\begin{tabular}{l|c|l}
\hline \multicolumn{1}{c|}{ TABLE 4} & \multicolumn{2}{|c}{ State Coverage } \\
\hline Drug Name & $\begin{array}{c}\text { Average } \\
\text { Coverage } \\
\text { Across States }\end{array}$ & \multicolumn{1}{c}{ Outlier State Coverage } \\
\hline Albenza & $69 \%$ & $\begin{array}{l}\text { Low: } 40 \% \text { in Georgia } \\
\text { High: } 100 \% \text { in Indiana, North Carolina, } \\
\text { New Jersey, Ohio, Pennsylvania }\end{array}$ \\
\hline Droxia & $58 \%$ & $\begin{array}{l}\text { Low: } 50 \% \text { in Arkansas, California, Ohio } \\
\text { High: } 100 \% \text { in Indiana, North Carolina, } \\
\text { New Jersey, Pennsylvania }\end{array}$ \\
\hline Sensipar & $83 \%$ & $\begin{array}{l}\text { Low: } 83 \% \text { in Ohio } \\
\text { High: } 100 \% \text { in all other states }\end{array}$ \\
\hline Votrient & $72 \%$ & $\begin{array}{l}\text { Low: } 50 \% \text { in Arkansas } \\
\text { High: } 100 \% \text { in California, Indiana, North } \\
\text { Carolina, New Jersey, Ohio, Pennsylvania }\end{array}$ \\
\hline Xenazine & $70 \%$ & $\begin{array}{l}\text { Low: } 60 \% \text { in Georgia } \\
\text { High: } 100 \% \text { in Arkansas, Indiana, North } \\
\text { Carolina, New Jersey, Pennsylvania }\end{array}$ \\
\hline Zavesca & $46 \%$ & $\begin{array}{l}\text { Low: } 0 \% \text { in New York } \\
\text { High: } 100 \% \text { in Indiana, North Carolina, } \\
\text { Pennsylvania }\end{array}$ \\
\hline Note: Average coverage is weighted by the number of plans in each state.
\end{tabular}

Note: Average coverage is weighted by the number of plans in each state.

(i.e., \$400) plus the coinsurance of the difference between the deductible and the full cost of the drug (i.e., $\$ 5,840$ ), totaling $\$ 6,240$ in the first month. In the second month, the patient will pay $40 \%$ coinsurance for the medication up to the plan's outof-pocket maximum (i.e., $\$ 6,250$ ), a sum of $\$ 10 .{ }^{26}$ In contrast, patients taking the same medication in a standard silver plan in New York will face no drug deductible and a flat $\$ 70$ copayment per month for this medication throughout the plan year. ${ }^{27}$ Benefit designs vary substantially from state to state and plan to plan. For patients with greater health needs, transparency of coverage and cost details would help improve the likelihood that they enroll in a QHP that best meets their needs.

While use of coinsurance among QHPs is widespread, it also highlights an inherent information gap for consumers. Since coinsurance is calculated based on the plan's negotiated pharmacy network rate, the exact dollar amount that would correspond to the coinsurance amount is not available. Without additional details, people comparing exchange plans will likely be unable to compare the actual out-of-pocket cost of a medication assigned a copayment (in dollars) with 1 assigned coinsurance (a percentage). Lack of adequate tools to compare out-of-pocket costs under coinsurance versus copayments at the time websites for the inaugural year launched illustrates the importance for patients to understand the coverage and cost of their treatments when choosing a QHP in the exchange. Managed care pharmacists may be on the front lines of receiving inquiries from patients regarding their options for coverage in exchange plans. In the absence of more transparent data, the pharmacist plays an enhanced role as educator and can assist rare disease patients and/or their caregivers with information on plans that will provide access to the care needed.
Additional disparities in readily available information challenge a patient's ability to directly compare marketplace plans. For example, in all but 1 state marketplace websites, viewing a plan's covered drugs requires a click to an external link and a search of a PDF or the plan's search tool to find out coverage details. These details may or may not include important information such as tier placement or UM requirements to ensure appropriate use of drugs. Further, external formularies are not displayed in any standardized method-some are searchable documents, while others are search engines. Patients seeking specific drug coverage and cost information will need to conduct additional research and may require assistance to find this information.

For patients with rare diseases, the process of identifying and selecting appropriate plans will likely center on ensuring that the plan covers a specific treatment or set of treatments. With limited treatment options and the potential for UM and cost-sharing requirements, navigating formularies will be a critical step for patients to understand the access picture in each plan. Policymakers and plans should consider enhancing tools to help patients navigate the plan selection process to find a plan that best meets their needs. Until additional enhancements are in place, managed care pharmacists can play an important role in educating rare disease patients on plans that will provide access to the care needed.

\section{Limitations}

This analysis examined the formularies of a select group of silver and bronze QHPs in a subset of states and does not offer a comprehensive view of all QHP formularies available nationwide. Additionally, the study was limited to the review of pharmacy benefit formularies and, therefore, did not include potential coverage of any of the selected products under the plans' medical benefits. The medications selected were not screened prior to selection for the route of administration, limiting the amount of data included across each analysis in this study. Further, the study focused only on coverage and access details obtained from publicly available sources and may not reflect the coverage and cost sharing for medications not listed on a plan's formulary but otherwise covered by the plan. Finally, the selection criteria for disease and drugs in this analysis were multifactorial and designed to focus on disease characteristics and drug availabilities rather than clinical or epidemiological reasons.

\section{Conclusions}

This preliminary analysis of coverage of treatments for patients with rare diseases reveals the complexities involved with selecting the plan that provides not only optimal coverage but also basic access for each patient. Already faced with limited treatment options, patients with rare diseases could experience even greater access challenges when researching and selecting plans within the health insurance exchanges. While there are potential safeguards and protections that can be implemented at the state or federal level to help ensure patient access to necessary and life-saving treatments, increasing transparency of needed information for patient decision making is equally important. 


\section{Authors}

SANDY W. ROBINSON, MPA, is Senior Vice President; KELLY BRANTLEY, MPH, is Senior Manager; and CHRISTINE LIOW, $\mathrm{MPH}$, is Manager, Avalere Health, LLC, Washington, DC. J. RUSSELL TEAGARDEN, MA, DMH, is Senior Vice President of Medical \& Scientific Affairs, National Organization for Rare Disorders, Danbury, Connecticut.

AUTHOR CORRESPONDENCE: Sandy W. Robinson, MPA, Senior Vice President, Avalere Health, LLC, 1350 Connecticut Ave., N.W., Ste.900, Washington, DC 20036. E-mail: srobinson@avalere.com.

\section{DISCLOSURES}

This research was supported by funding from Novartis Pharmaceuticals Corporation, East Hanover, New Jersey.

Robinson, Teagarden, and Brantley collaborated on study concept and design. Data collection was performed mainly by Brantley and Liow, assisted by Robinson, and all authors collaborated on data interpretation. The manuscript was written by Liow, Brantley, Robinson, and Teagarden and revised by Robinson, Brantley, and Teagarden, with assistance from Liow.

\section{ACKNOWLEDGMENTS}

The authors acknowledge the contributions of Jenny Gaffney, Director, Avalere Health, LLC, and Novartis Pharmaceuticals Corporation on concept/ design and review/revision of the manuscript. Avalere retained editorial control over the manuscript.

\section{REFERENCES}

1. Designation of an Orphan Drug, 21 CFR 316.20 (2012). Available at: http://www.ecfr.gov/cgi-bin/text-idx? rgn=div5\&node=21:5.0.1.1.6\# se21.5.316_120. Accessed August 28, 2014.

2. National Center for Advancing Translational Sciences. FAQ about rare diseases. Available at: http://www.ncats.nih.gov/about/faq/rare/rare-faq.html. Accessed August 17, 2014.

3. National Institutes of Health. NIH announces new program to develop therapeutics for rare and neglected diseases. Press release. May 20, 2009. Available at: https://rarediseases.info.nih.gov/files/TRND\%20Press\%20 Release.pdf. Accessed August 17, 2014.

4. Orphan-Drug Exclusive Approval, 21 CFR 316.31 (2012). Available at: http://www.ecfr.gov/cgi-bin/text-idx? rgn=div5\&node=21:5.0.1.1.6\# se21.5.316_131. Accessed August 28, 2014.

5. Designation of HUD status, 21 CFR 814.102 (2013). Available at: http:// www.ecfr.gov/cgi-bin/text-idx?SID=21cf9549ae749be56dde7c149f86ef10\&n ode=sp21.8.814.h\&rgn=div6. Accessed August 28, 2014.

6. Faden L, Huskamp H. Appendix C: Medicare Part D coverage and reimbursement of orphan drugs. In: Field MJ, Boat TF, eds. Rare Diseases and Orphan Products: Accelerating Research and Development. Washington, DC: National Academies Press; 2010:309-43. Available at: http://www.ncbi.nlm. nih.gov/books/NBK56190/. Accessed August 17, 2014.

7. Institute of Medicine. Rare diseases and orphan products: accelerating research and development. Report brief. October 4, 2010. Available at: http:// www.iom.edu/ /media/Files/Report\%20Files/2010/Rare-Diseases-and-OrphanProducts-Accelerating-Research-and-Development/Rare\%20Disease\%20 Research\%202010\%20Report\%20Brief.pdf. Accessed August 17, 2014

8. Coverage of Essential Health Benefits, 45 CFR 156.140 (2012). Available at: http://www.ecfr.gov/cgi-bin/text-idx?SID=0659la443a74al7909f2f9db0d 023efe\&node $=$ se 45.1.156_1140\&rgn=div8. Accessed August 28, 2014.

9. The Patient Protection and Affordable Care Act, Public Law 111-148. March 23, 2010. Available at: http://www.gpo.gov/fdsys/pkg/PLAW11lpubl148/pdf/PLAW-111publ148.pdf. Accessed September 8, 2014.
10. Coverage of Essential Health Benefits, 45 CFR 147.150 (2012). Available at: http://www.ecfr.gov/cgi-bin/retrieveECFR?gp=\&SID=1787c2cea700807b 70c897eacafd3eb0\&r=PART\&n=45y1.0.1.2.62\#se45.1.147_1150. Accessed August 28, 2014.

11. Prescription Drug Benefit, 45 CFR 156.122 (2012). Available at: http:// www.ecfr.gov/cgi-bin/retrieveECFR?gp $=\& S I D=7 a 1068$ a2d7eld358338889 6e360ld4c0\&n=sp45.1.156.b\&r=SUBPART\&ty=HTML\#se45.1.156_1122. Accessed August 28, 2014.

12. United States Pharmacopeia. Medicare Model Guidelines Version 5.0. 2011. Available at: http://www.usp.org/sites/default/files/usp_pdf/EN/healthcare Professionals/2011-03-1luspmgcatclass.pdf. Accessed August 17, 2014.

13. Center for Consumer Information \& Insurance Oversight (CCIIO). Letter to issuers on federally-facilitated and state partnership exchanges. April 5, 2013. Available at: http://www.cms.gov/CCIIO/Resources/ Regulations-and-Guidance/Downloads/2014_letter_to_issuers_04052013. pdf. Accessed August 17, 2014.

14. Center for Consumer Information \& Insurance Oversight (CCIIO). Additional information on proposed state essential health benefits benchmark pans. Available at: http://www.cms.gov/cciio/resources/data-resources/ ehb.html. Accessed August 17, 2014.

15. Office of Rare Diseases Research. Rare diseases with FDA-approved medical products. Available at: http://rarediseases.info.nih.gov/gard/diseaseswith-medical-products/A. Accessed August 17, 2014.

16. U.S. Food and Drug Administration. Search orphan drug designations and approvals. Available at: http://www.accessdata.fda.gov/scripts/opdlisting/oopd/. Accessed August 17, 2014.

17. Soliris (eculizumab) prescribing information. Alexion Pharmaceuticals, Inc. Revised April 2014. Available at: http://soliris.net/sites/default/files/ assets/soliris_pi.pdf. Accessed August 17, 2014

18. Ceredase (alglucerase injection) prescribing information. Genzyme Corporation. February 9, 2006. Available at: http://www.accessdata.fda.gov/ drugsatfda_docs/label/2006/020057s034lbl.pdf. Accessed August 17, 2014.

19. Cerezyme (imiglucerase for injection) prescribing information. Genzyme Corporation. 2002. Available at: http://www.cerezyme.com/ /media/ CerezymeUS/Files/pdf/cerezyme_pi.pdf. Accessed August 17, 2014.

20. Elelyso (taliglucerase alfa) prescribing information. Pfizer Labs. Revised May 2014. Available at: http://www.elelyso.com/pdf/ELELYSO_Prescribing_ Information.pdf. Accessed August 17, 2014.

21. Vpriv (velaglucerase alfa for injection) prescribing information. Shire Human Genetic Therapies, Inc. Revised August 2013. Available at: http:// www.vpriv.com/app_presentation/vpriv/images/pdf/VPRIV_PI_Prescribing_ Information.pdf. Accessed August 17, 2014.

22. Unpublished data from Avalere Health Enrollment Model. Scenario 2 (assumes 24 states opt out of the Medicaid expansion). December 2013.

23. The Kaiser Family Foundation. Focus on health reform. Patient costsharing under the Affordable Care Act. April 2012. Available at: http:// kaiserfamilyfoundation.files.wordpress.com/2013/01/8303.pdf. Accessed August 17, 2014

24. U.S. Department of Health and Human Services. Office of the Assistant Secretary for Planning and Evaluation. Health insurance marketplace: summary enrollment report for the initial annual open enrollment period. ASPE Issue Brief. May 1, 2014. Available at: http://aspe.hhs.gov/health/ reports/2014/MarketPlaceEnrollment/Apr2014/ib_2014Apr_enrollment.pdf. Accessed August 17, 2014.

25. Cost-Sharing Requirements, 45 CFR 156.130 (2012). Available at: http:// www.ecfr. gov/cgi-bin/text-idx?type $=$ simple $; \mathrm{c}=$ ecfr;cc $=$ ecfr; $;$ idno $=45 ;$ region $=$ DI Vl;ql=155;rgn=div5;sid=7fda22484d8dcdd44f869475d74823d6;view=text;n ode $=45 \% 3$ A1.0.1.2.71\#se45.1.156_1130. Accessed August 28, 2014.

26. ConnectiCare. Standard silver point-of-service. HD 3000 silver plan. Summary of benefits and coverage. 2014. Available at: http://www.connecticare.com/globalfiles/sbc/POS-OA-30-45-3000HD-CAL-HIXS-F.pdf. Accessed August 17, 2014.

27. NY State of Health. Standard silver plan. Schedule of benefits, pp 6-10 Available at: http://www.healthbenefitexchange.ny.gov/sites/default/files/ Standard\%20Products.pdf. Accessed August 17, 2014. 